\title{
Atuação da empresa Bunge no Brasil: um estudo de caso sobre sua importância na
}

\section{economia local}

\author{
Bunge's performance in Brazil: a case study on its importance in the local economy
}

Recebido: 28/10/2021 | Revisado: 03/11/2021 | Aceito: 09/11/2021 | Publicado: 11/11/2021

\author{
Hugo Pereira da Silva \\ ORCID: https://orcid.org/0000-0001-8898-2245 \\ Universidade Federal de Campina Grande, Brasil \\ E-mail: hugopereiradasilva2020@gmail.com \\ Isabel Lausanne Fontgalland \\ ORCID: https://orcid.org/0000-0002-0087-2840 \\ Universidade Federal de Campina Grande, Brasil \\ E-mail: isabelfontgalland@gmail.com
}

\begin{abstract}
Resumo
A Bunge é uma empresa transnacional, que atua na área de agronegócios e alimentos, com matriz em St. Louis (Missouri). Verticalmente integrada, a empresa Bunge comercializa e processa grãos como (soja, trigo e milho), produz alimentos (óleos, margarinas, maioneses, azeites, arroz, atomatados, farinhas e purê misturas para bolos), e também produz açúcar e bioenergia. Sua atuação em serviços portuários e de logística é muito influente nos Estados Unidos e no Brasil é a principal empresa do ramo agroalimentar com a mais expressiva taxa de exportação de grãos do país. A Bunge comporta cerca de 100 instalações, entre fábricas, usinas, moinhos, portos, centros de distribuição e silos, em 14 estados e no Distrito Federal. É detentora de várias marcas, incluindo como: Salada, Soya, All Day, Cardeal, Delícia, Primor, Etti, Salsaretti e Bunge Pro. O objetivo do presente estudo foi apresentar a atuação da empresa e seu mix de produtos sua importância para a economia local. Foram observados vários dados provenientes de relatórios internos da Bunge e apontar a trajetória de sucesso da inovação.
\end{abstract}

Palavras-chave: Bunge; Empresa; Alimentos; Brasil; Economia.

\begin{abstract}
Bunge is a multinational company operating in the American agribusiness and food sector, headquartered in St. Louis (Missouri). St. Louis is an independent city located in the US state of Missouri, on the border with the state of Illinois. Located at the confluence of the Mississippi River and the Missouri River, it is one of the main cities in the American Midwest. Vertically integrated, the Bunge company sells and processes grains such as (soybeans, wheat and corn), produces food (oils, margarines, mayonnaise, olive oil, rice, tomato, flour and premixes for cakes), operates in port and logistics services and produces sugar and bioenergy. Its operations in Brazil are very important for the economy, where it is the main company in the agri-food sector with the largest export in the country. It has more than 20,000 employees, working in around 100 facilities, including factories, mills, mills, ports, distribution centers and silos, in 14 states and the Federal District. It owns several brands, including: Salada, Soya, All Day, Cardinal, Delícia, Primor, Etti, Salsaretti and Bunge Pro. This case study aims to present the characteristics of the Bunge company in Brazil and its importance for the local economy.
\end{abstract}

Keywords: Bunge; Company; Foods; Brazil; Economy.

\section{Introdução}

A história da Bunge iniciou em 1818, quando foi fundada a Bunge \& Co., em Amsterdam, Holanda por um negociante de origem alemã, conhecido como Johannpeter G. Bunge. Ele comercializava grãos importados das colônias holandesas. Alguns anos depois, a sede da empresa mudou-se para Rotterdam e foram abertas as subsidiárias em outros países europeus. Atualmente, a Bunge Limited é uma empresa global, com sede em White Plains, Nova Iorque, Estados Unidos, líder do agronegócio no mundo e produtos alimentícios variados, contando com aproximadamente 35.000 funcionários em mais de 40 países. 
No Brasil, a trajetória da Bunge teve início no ano de 1905, quando ela começa a participar minoritariamente do capital da S.A. Moinho Santista Indústrias Gerais, empresa de compra e moagem de trigo de Santos no Estado de São Paulo. Iniciou-se uma célere expansão no país com a aquisição de diversas empresas nos ramos de alimentação e agronegócio. Alguns anos depois, em 1923, a Bunge compra a empresa Cavalcanti \& CIA., em Recife, no estado de Pernambuco, onde resultou na formação da Sanbra, posteriormente denominada Santista alimentos. Em 1938, ela passa a comercializar fertilizantes, com a constituição da Serrana S.A. de Mineração. Para aumentar sua participação neste mercado, em 1997, ela compra a IAP, tradicional empresa do agronegócios no país. Nos anos seguintes, outras duas grandes empresas de fertilizantes são incorporadas à Bunge: a Ouro Verde e a Manah. Para a área de alimentos, em 1997 também foi um importante ano, marcado pela aquisição da líder no processamento de soja e produção de farelos e óleos, Ceval alimentos. Em 2007, a empresa adquire sua primeira usina de cana-de-açucar em Santa Juliana, MG. Um ano depois assume o controle da Usina Monteverde em Ponta Porã, MS, e inicia a construção de uma terceira usina em Pedro Afonso, TO. No ano de 2010, a empresa unifica suas atividades sob o comando do ex-ministro Pedro Parente, vende a sua área de mineração de nutrientes para fertilizantes a Vale e adquire a Moema Par, holding com cinco usinas de cana-de-açúcar, localizada em São Paulo e Minas Gerais. Em 2013, a Bunge vende as fábricas e operação de distribuição de fertilizantes no Brasil para a Yara Internacional ASA. No ano de 2014, Pedro Parente anuncia a sua aposentadoria da empresa sendo substituído por Raul Padilla como presidente e CEO da Bunge Brasil. Em 2014, a Bunge inaugura o complexo portuário Miritituba - Barcarena, que envolve a estação de transbordo, em Miritituba, o terminal portuário Fronteira Norte (Terfron), localizado em Barcarena, ambos no Pará. Atualmente, a Bunge possui cerca de 150 unidades operacionais no país, entre fábricas, moinhos, usinas, silos, centro de distribuição e portos.

Instalada em 19 estados e no Distrito Federal, a Bunge do Brasil é a gigante de agronegócio e alimentos. Seus produtos chegam a $77 \%$ dos lares brasileiros, e em mais de 4,6 mil municípios. Cobrindo desta forma, $83 \%$ das cidades brasileiras. Na Figura 1, visualiza-se a área externa da empresa organizada.

Figura 1 - Empresa Bunge Alimentos.

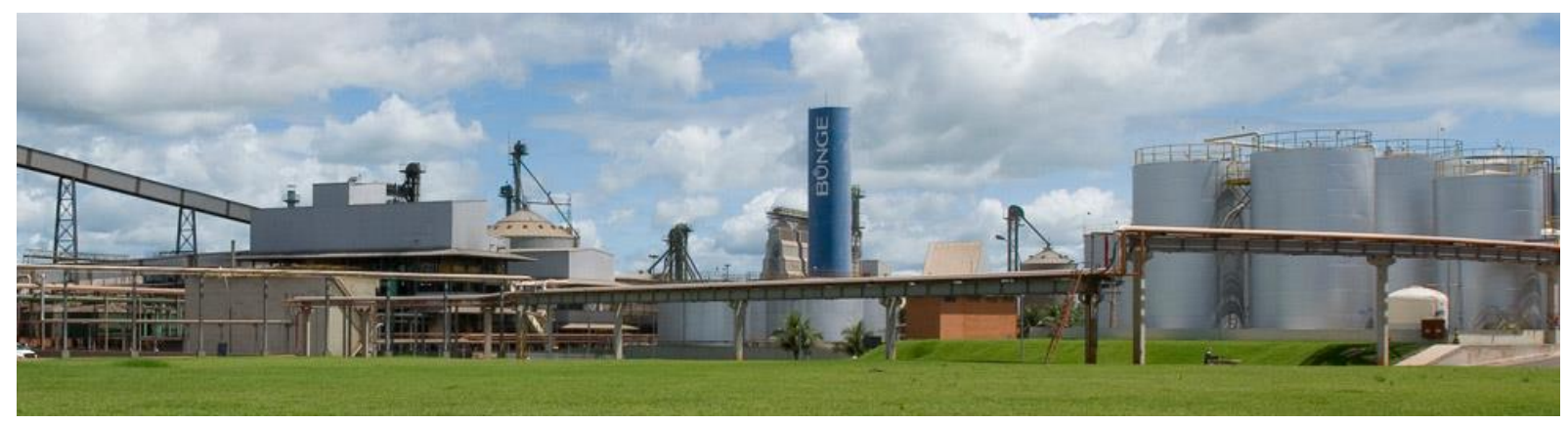

Fonte: Arquivos Bunge (2021).

Essas áreas estão organizadas em Açúcar e Bioenergia, Agronegócio \& Logística, Alimentos \& Ingredientes e Fertilizantes. Dessa maneira, a Bunge Brasil opera de forma integrada e está presente do campo à mesa do consumidor. A empresa produz e comercializa fertilizantes que aumentam a produtividade no campo, compra e processa grãos (soja, trigo, milho, algodão, arroz e outras commodities), fabrica alimentos para o consumidor final e indústria (óleos, margarinas, farinhas e misturas para panificação, molhos e temperos, entre outros) e produz açúcar, etanol e biodiesel. A Bunge ainda provê serviços logísticos e portuários para o escoamento de seus produtos.

A Bunge do Brasil, desde sua fundação, em 1955, atua em diferentes frentes, que têm em comum a valorização das pessoas e do conhecimento. Na prática essa atuação se dá por meio de:

$\checkmark$ Preservação e gestão da memória empresarial; 


\footnotetext{
$\checkmark$ Desenvolvimento sustentável de comunidades locais;

$\checkmark$ Promoção da leitura e do prazer de ler;

$\checkmark$ Estímulo ao voluntariado corporativo;

$\checkmark \quad$ Incentivo às ciências, às letras e às artes.
}

\section{Metodologia}

Neste estudo, foi utilizado a metodologia de estudo de caso, tendo por empresa a BUNGE do Brasil. Os estudos de caso foram um dos primeiros tipos de pesquisa a serem usados no campo da metodologia qualitativa. Hoje, eles respondem por uma grande proporção da pesquisa apresentado em livros e artigos de psicologia, história, educação e medicina, para listar apenas algumas das ciências fundamentais. Muito do que se sabe hoje sobre o mundo empírico, foi produzido por pesquisas de estudo de caso, e muitos dos clássicos mais valorizados em cada disciplina são estudos de caso (Flyvbjerg 2011, p. 302). Os estudos de caso têm sido amplamente utilizados nas ciências sociais e têm sido considerado especialmente valioso em campos orientados para a prática (como educação, gestão, administração pública e serviço social). Mas, apesar dessa longa história e uso generalizado, a pesquisa de estudo de caso tem recebido pouca atenção entre as várias metodologias de pesquisa em ciências sociais.

\section{Resultados e Discussão}

\section{1 Áreas de Negócios}

No mercado Brasileiro, a empresa Bunge atua por meio de quatro áreas de negócios que possibilitam a integração com a cadeia de valor do campo à mesa: Açúcar e Bioenergia, Agronegócio \& Logística, Alimentos \& Ingredientes e Fertilizantes. Com sinergia entre esses seguimentos de negócios, a empresa tem conseguido reduzir seus custos de produção, aperfeiçoar seus processos, atender os clientes com cada vez mais agilidade e promover a geração de valor compatível com os interesses dos acionistas, com o desenvolvimento sustentável da sociedade e com o crescimento econômico e social do Brasil.

Os investimentos da Bunge buscam o fortalecimento do portfólio de produtos e sua atuação integrada em todo o país. Um exemplo é a compra da área de alimentos da Hypermarcas por R\$ 180 milhões, agregando as marcas Etti, Salsaretti e Cajamar aos segmentos de molhos e extratos de tomate, caldos, molhos e temperos, pratos prontos e instantâneos no fim de 2011. Com o negócio a Bunge adquiriu também uma fábrica e um centro de distribuição em Araçatuba (SP).

\subsubsection{Inovação Contínuada}

A inovação contínua de seus produtos e processos operacionais é um dos caminhos para que a Bunge alcance a excelência operacional de maneira integrada. O programa Inova Bunge, que abriga o banco de ideias, destinado a receber sugestões de melhorias em produtos, serviços e processos provenientes de todos os profissionais da companhia. Além de trazer valor para o cliente, a proposta possibilita aumentar a rentabilidade e a produtividade da empresa. Foram geradas 514 ideias, relacionadas diretamente as iniciativas de sustentabilidade tais como redução do consumo de água, energia, geração de resíduos e qualidade de vida, sendo que 67 ideias foram implementadas. No ano de 2012, o programa Inova foi implantado definitivamente na área de Açúcar \& Bioenergia, consolidando sua aplicação em todos os negócios da Bunge Brasil. Além disso, o projeto deu início ao desenvolvimento de uma nova ferramenta, a Eureka, que trará uma metodologia para o fortalecimento de ideias que buscam a criação de novos negócios.

Os gráficos á seguir irão mostrar o desenvolvimento das ideias geradas e das implementadas entre os anos de 2009 á 2012 da empresa Bunge. 
Gráfico 1. Levantamento de ideias geradas entre 2009 à 2012.

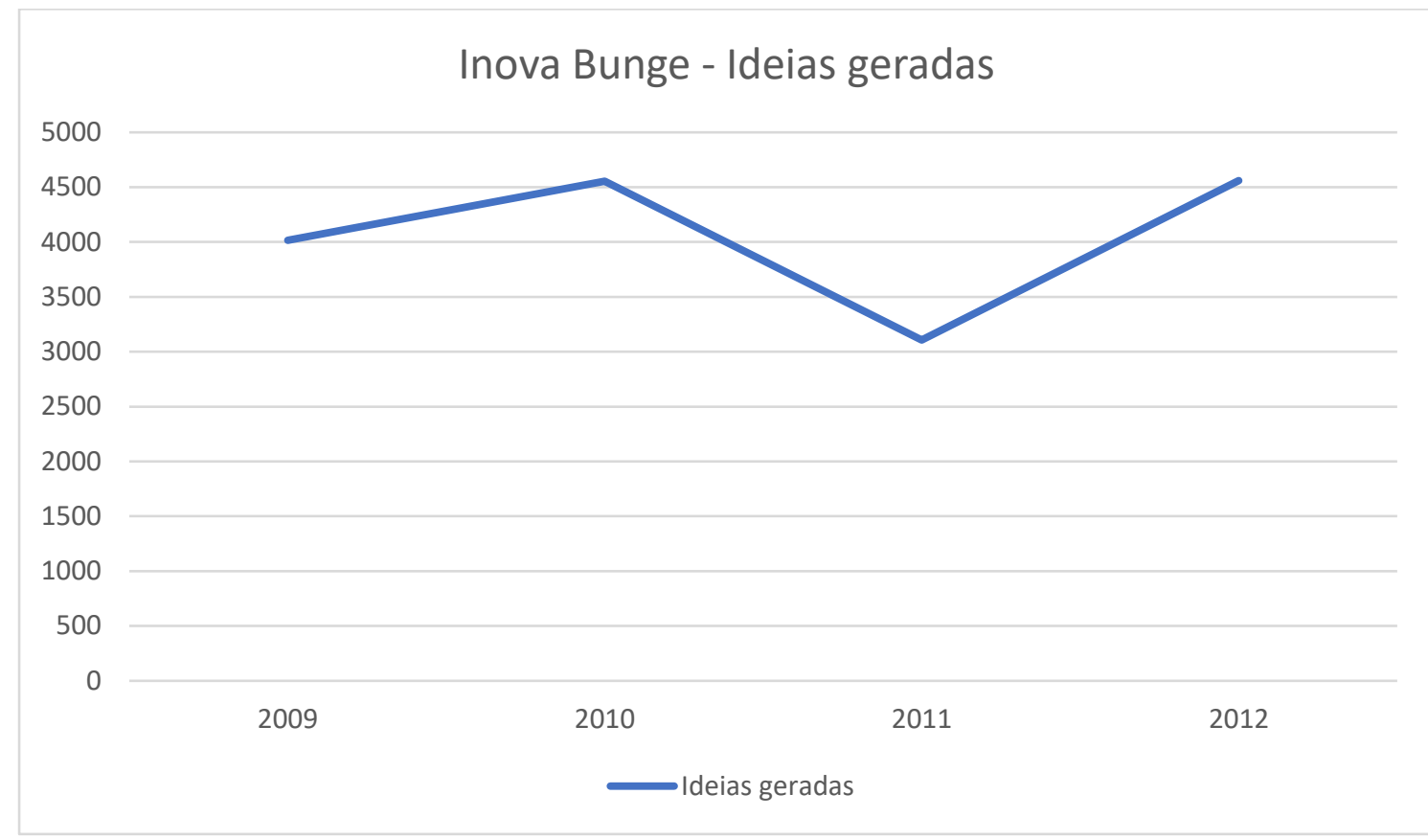

Fonte: Autores.

Analisa-se no Gráfico 1 que houve uma crescente evolução nas ideias através de patentes geradas para a inovação e desenvolvimento com os chamados projetos PIDD.

Gráfico 2. Levantamento de ideias implementadas entre 2009 à 2012.

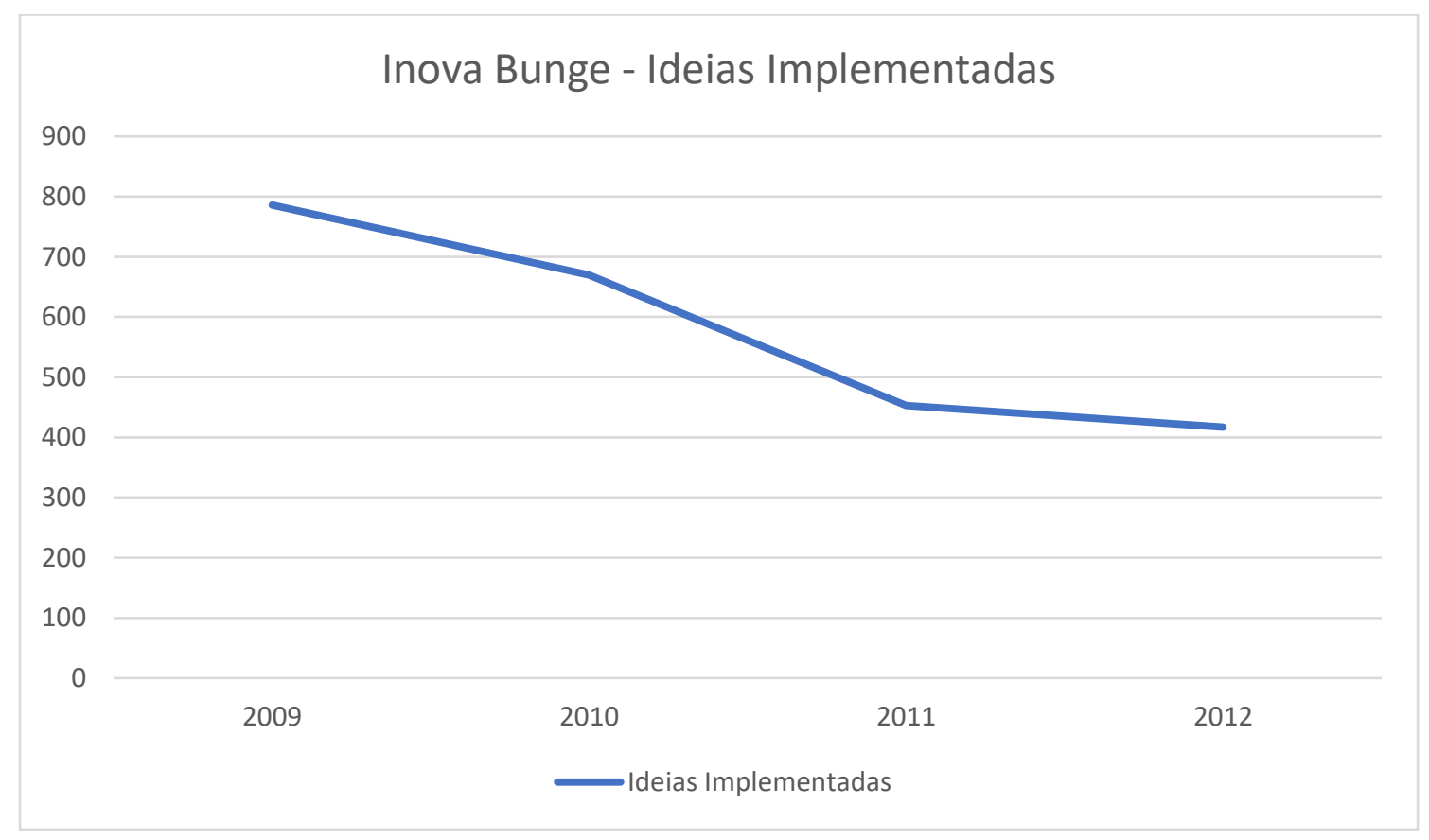

Fonte: Autores.

\section{Informações financeiras validadas com Controladoria e Desempenho de Negócio}

Analisa-se no Gráfico 2 que houve uma regressão em relação as ideias implementas entre os anos de 2009 à 2012, pois nem todas as ideias geradas entre os respectivos anos foram colocadas em prática. 


\subsubsection{Agronegócio}

A Bunge do Brasil originariamente, processa e movimenta dezenas de milhões de toneladas de commodities por ano, conectando produtores a consumidores em todo o país. É líder global na produção, processamento e comercialização de oleaginosas e é uma das maiores exportadoras do Brasil no agronegócio e em todos os setores. Considerada uma das maiores movimentadoras de carga no Brasil, por ano, são feitas aproximadamente 630 mil viagens de caminhões, 160 mil de vagões, 60 viagens de barcaças e 770 escalas de navios transportando grãos, óleos vegetais, entre outros.

\subsubsection{Alimentos \& Ingredientes}

A Bunge é a líder nacional nos mercados de óleos, farinhas e pré-misturas para panificação, oferece um amplo portfólio de produtos para atender às necessidades de seus consumidores e clientes. Como líder mundial no processamento de sementes oleaginosas e na produção e fornecimento de óleos e gorduras vegetais especiais, a Bunge valoriza parcerias com os agricultores para melhorar a produtividade e a eficiência ambiental da agricultura nas cadeias de valor, levando produtos com qualidade de onde eles são produzidos para onde são consumidos. A Bunge sempre teve o diferencial de inovação, investindo em novos produtos com tecnologias inovadoras e empreendimentos para criar vantagens inigualáveis, serviços originais e soluções criativas. Na figura 2 á seguir está todos os produtos que são fabricados na empresa, que levam consigo a marca Bunge.

Figura 2 - Produtos da marca Bunge.
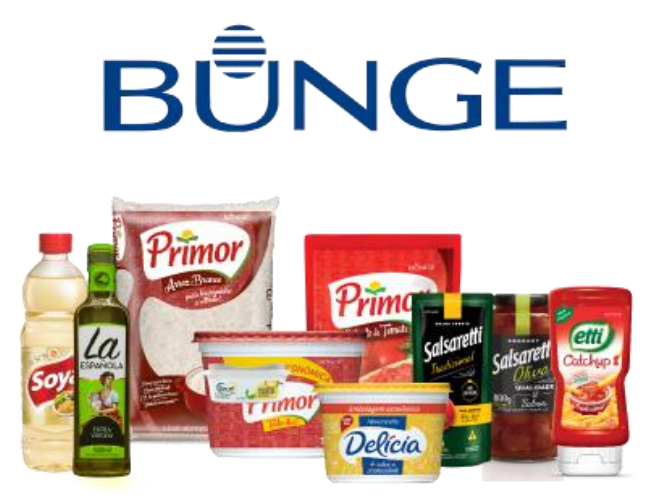

Fonte: Produtos Bunge - Arquivos Bunge (2021).

\subsubsection{Açúcar \& Bioenergia}

Em 2019 a Bunge anunciou a joint venture com a BP, criando a Bunge Bioenergia, considerada como uma das líderes na produção de etanol, açúcar e bioenergia no Brasil. Já nasceu entre as líderes dos setores de bioenergia no Brasil, um dos mercados de biocombustíveis que mais cresce no mundo.

\subsection{Indústria Bunge}

Com excelentes unidades fabris, distribuídas pelo país, com alta tecnologia e excelente infraestrutura e capital de alta qualidade, a Bunge oportuniza atender a complexidade de cada mercado e desenvolver em conjunto, alternativas inteligentes, sustentáveis e rentáveis para alavancar novos negócios perante o comércio Brasileiro. A Bunge possui marcas de tradição e qualidade com amplo portfolio para nossos consumidores e clientes. Com uma presença de marca crescente em 75,5\% dos lares Brasileiros, durante seus mais de 110 anos de história contribuindo para a construção de uma alimentação mais saudável e sustentável no país. Com um revolucionamento de hábitos alimentares, a Bunge trouxe para o dia a dia dos Brasileiros inovações 
como a primeira pré-mistura para bolos e o primeiro óleo vegetal mais saudável que a banha de porco, usada até então. A empresa foi pioneira na criação do centro de atendimento ao consumidor.

\subsection{Marca de Sustentabilidade}

Os pilares que abrangem:

$\checkmark$ Iniciativas para questões climáticas: implementação de soluções inovadoras para minimizar a pegada ambiental, apoiando projetos e atividades que fortalecem a abordagem no combate às mudanças climáticas;

$\checkmark$ Cadeia de suprimentos responsável: Promove uma agricultura sustentável e implementa projetos robustos que protegem e restauram o meio ambiente, ao mesmo tempo em que apoia o bem-estar social e econômico dos produtores e comunidades locais;

$\checkmark$ Compromisso com a transparência: Líder de transparência no setor, elevando o nível de desempenho no setor, acompanhando e divulgando regularmente o progresso em compromissos e desempenhos na área de sustentabilidade.

A Bunge acredita que a sua posição de liderança no sistema alimentar global permite unir todas as partes interessadas, de agricultores a consumidores, ongs e governos, promovendo ações que ajudem a apoiar a agricultura sustentável.

\subsection{Bunge 100 anos}

No ano de 2005, quando a Bunge completa seu centenário, foi lançado o projeto "Bunge 100 anos pensando o futuro", um projeto de sustentabilidade, investimento em cidadania, cultura, meio ambiente e qualidade de vida. Gerar desenvolvimento econômico e manter os olhos com foco, nos aspectos socioambientais direta ou indiretamente vinculados às operações industriais, são sinônimos de sustentabilidade e respeito ao meio-ambiente. Responsabilidade na Bunge é um conceito sério, afinado com os valores que regem as empresas do grupo no mundo: integridade, sinceridade e confiança, trabalho em equipe, compromisso, espírito empreendedor, foco no produtor rural/cliente. Em respeito a esses valores, a Bunge faz da prática da cidadania e da responsabilidade social instrumentos para a formulação de políticas que assegurem a conservação do meio ambiente, única forma de viabilizar o amanhã e de fazer com que o Brasil cumpra a missão que lhe está reservada: ser o celeiro do mundo. A Bunge visa muito a questão de responsabilidade ambiental, com olhar atento à qualidade de vida no futuro, educar para preservar. Fortalecer alianças que promovam a sustentabilidade no campo, produzir com responsabilidade, em nome do respeito às gerações que estão por vir.

\section{5 Ênfase nas áreas de desenvolvimento}

Com forte presença nas áreas de desenvolvimento do país, a fim de promover melhores condições às comunidades locais e melhorias dos serviços, a empresa avalia com os stakeholders locais, as necessidades de investimentos, em infraestrutura pública. Esses investimentos trazem muitos benefícios a todos os instalados localmente, aceleram o desenvolvimento, promovem bem-estar e progresso técnico regional e nacional. A informação individualizada, sobre os incentivos negociados nos respectivos locais, onde tenham acontecido é considerada confidencial para a empresa. A empresa apoia a melhoria da infraestrutura socialurbana. Em 2012, impulsionou o desenvolvimento da infraestrutura pública nas áreas de saneamento básico, logística e distribuição de energia elétrica na região Norte. Os valores destinados a tais ações, totalizaram no período, $\mathrm{R} \$ 6.108 .000$. Importante ressaltar que, desse valor, o montante de R\$ 5 milhões referiu-se a um acordo com a empresa de distribuição de energia elétrica do Pará, na viabilização de projeto que beneficiou a comunidade de Miritituba. 


\subsection{Desempenho Econômico da Bunge}

O desempenho está diretamente ligado à dinâmica das economias locais e regionais. O planejamento e a gestão das principais operações da Bunge consideram o impacto que trazem aos respectivos municípios nos quais estão localizados. Uma das principais ações para promover o desenvolvimento regional estão o investimento na qualificação da mão-de-obra, a avaliação conjunta com o poder público das necessidades das comunidades e a preferência pela contratação de profissionais e prestadores de serviços locais. Gerações de emprego e renda, investimento social privado e promoção dos direitos humanos são os principais impactos das operações da Bunge na sociedade. Sempre procura atingir o objetivo de oferecer produtos e serviços cada vez mais benéficos e, ao mesmo tempo, manter em processo de melhoria contínua o relacionamento com seus diversos públicos de interesses.

Entre 2007, 2008 e 2009 a Bunge teve ótimos resultados financeiros entre vendas líquidas e lucro líquido.

> 2007: 18,6 bilhões de vendas líquidas, resultando 53 milhões de lucro líquido;

> 2008: 31,4 bilhões de vendas líquidas, resultando 219,1 milhões de lucro líquido;

> 2009: 25,9 bilhões de vendas líquidas, resultando 349,4 milhões de lucro líquido.

A Bunge recebe, sempre de forma pontual, ajuda financeira indireta de governos municipais e estaduais para a instalação ou ampliação de empreendimentos industriais ou agro industriais considerados prioritários, que possam impactar positivamente a economia local. Esses impactos são medidos por meio de geração de renda, emprego para a mão de obra local, com aquisição de matérias-primas produzidas localmente e potencial influência na criação de micro e pequenas empresas. A participação dos governos se dá por meios de incentivos fiscais, financiamentos em condições especiais e doações de terrenos.

\subsubsection{Investimento Social Privado}

A Bunge Brasil tem um investimento social privado que é direcionado ao desenvolvimento das comunidades nas regiões em que a empresa opera. No ano de 2012, foram destinados $R \$ 4,8$ milhões a projetos de desenvolvimento sustentável, educação, conscientização ambiental e memória corporativa. Estratégia relacionada à percepção de que o crescimento sustentável da empresa depende de um planejamento de longo prazo e da conscientização da sociedade para a importância da preservação dos recursos naturais.

\subsection{Resultados de melhores práticas}

A Bunge, uma das líderes globais em agronegócio, alimentos e ingredientes está na primeira colocação na lista Setorial Agronegócio do Ranking Merco de Responsabilidade e Governança Corporativa 2020, sendo o terceiro ano consecutivo em que a companhia figura no topo do recorte setorial de agronegócios. No ranking das 100 empresas brasileiras mais responsáveis e com melhor governança corporativa, a Bunge ocupa a 59 colocação. A companhia subiu 11 posições de melhoria em comparação com o ranking de 2019, quando ocupou o $70^{\circ}$ lugar. Para a Bunge, manter uma posição de liderança no ranking setorial de agro e melhorar significativamente sua colocação entre as 100 empresas mais responsáveis do Brasil é um reconhecimento importante de todos os esforços para adoção das melhores práticas em seus negócios e em apoio à sua cadeia de valor

\section{Conclusão}

A Bunge tem impactos positivos na economia com geração de emprego e renda, investimento social privado e promoção dos direitos humanos, são os principais impactos de suas operações na sociedade, sempre procurando atingir o objetivo de oferecer produtos cada vez mais benéficos e, ao mesmo tempo, manter em processo de melhoria contínua o relacionamento com seus diversos públicos de interesse. É uma das maiores empresas de agronegócios e alimentos do Brasil considerada também 
uma das maiores exportadoras, tendo um dos maiores crescimentos da economia local. A empresa ocupou o terceiro lugar no ranking ao longo de todo o ano de 2012 e, historicamente, se mantém como grande destaque do setor agrícola na balança comercial brasileira. Foi exportado US\$ 797 milhões no mês de julho, 21\% a mais que no mesmo período do ano passado. No acumulado dos primeiros sete meses de 2013, as vendas externas da empresa foram 9,5\% maiores do que em 2012, somando US\$ 4,5 bilhões. Ainda em 2012, considerando todas as áreas de negócio que a empresa atua, a Bunge Brasil alcançou receita bruta de R $\$ 33,7$ bilhões, um acréscimo de $16 \%$ sobre o faturamento bruto do ano anterior. O faturamento líquido das operações da empresa no Brasil no ano de 2012 representou 27\% do resultado da Bunge globalmente, o que demonstra a importância da operação brasileira.

Atualmente a subsidiária Brasileira, uma das mais importantes do grupo no mundo, fatura mais de R $\$ 40$ bilhões, emprega 20.000 pessoas e possui mais de 100 unidades entre fábricas, instalações portuárias, usinas, moinhos, centros de distribuição e silos, instalados em 17 estados do país. Além disso, a empresa compra de aproximadamente 20 mil produtores rurais um volume em torno de 20 milhões de toneladas de grãos, entre soja, milho, trigo, caroço de algodão, sorgo e girassol, se relaciona regularmente com clientes em quase 30 países. É a maior processadora de trigo da América Latina, comprando e beneficiando aproximadamente 2 milhões de toneladas do grão por ano. Além disso, a Bunge produz etanol suficiente para abastecer aproximadamente 240 mil veículos por mês. Os produtos Bunge estão em $80 \%$ das residências do país e em mais $70 \%$ das padarias. Nos mais de 100 anos de história no Brasil, a Bunge participou ativamente para concretizar a vocação brasileira de grande produtora de alimentos.

Conclui-se, assim, que a empresa Bunge tem contribuído para o desenvolvimento da economia brasileira seja local ou regional. A relação emprego/renda, distribuição de alimentos, e questões sustentáveis formam o tripé de seus projetos. Outrossim, a empresa tem como mitigador a economia circular, associand o desenvolvimento econômico a um melhor uso de recursos naturais, gerando por meio de novos modelos de negócios e da otimização nos processos de fabricação, priorizando insumos mais duráveis, recicláveis e renováveis. Faz parte também, de um modelo de diversificação horizontal, consistindo sempre na introdução de novos produtos que de alguma forma estejam relacionados com os produtos originais da empresa em questão explorando economias de escopo e os canais de venda disponíveis para a empresa.

\section{Referências}

Bunge. Wikipédia, (2021). Bunge - Wikipédia, a enciclopédia livre (wikipedia.org).

Bunge Brasil. Linked in, (2021). https://br.linkedin.com/company/bungebrasil.

Bunge: Nossa História. Bunge, (2021). https://www.bunge.com.br/Bunge/Nossa_Historia.aspx.

A Bunge: Cultura e Valores. Bunge, (2021). https://www.bunge.com.br/Bunge/Cultura_e_Valores.aspx.

Fontgalland, I. (2021). MEC - Slides, UFCG

Fundação Bunge. Bunge, 2021. https://www.bunge.com.br/Bunge/Fundacao_Bunge.aspx.

Kupfer, d. \& Hasenclever, L. (2013) Economia Industrial

Sustentabilidade: Nossos princípios. Bunge, 2021. https://www.bunge.com.br/Sustentabilidade/Nossos_Principios.aspx.

Relatório de Sustentabilidade (2004). Bunge, 2004.https://www.bunge.com.br/downloads/sustentabilidade/bunge_relatorio_sustentabilidade_2004.pdf.

Relatório de Sustentabilidade (2013). Bunge, 2013. https://www.bunge.com.br/sustentabilidade/2013/port/downloads/Bunge_RA12.pdf.

Área de negócios. Bunge Brasil, (2021). https://www.bunge.com.br/sustentabilidade/2013/port/ra/14.htm\#.YV0JJNrMLIV.

Ranking setorial do agronegócio. Bunge Brasil, (2021). https://www.bunge.com.br/Imprensa/Noticia.aspx?id=1328.

Desempenho econômico. Bunge, (2010). https://www.bunge.com.br/sustentabilidade/2010/pt-br/desempenho-economico/index.html.

Carreiras: Nossa Atuação. Bunge, (2021). https://www.bunge.com.br/Carreiras/Nossa_Atuacao.aspx. 
Bunge. Mundo das marcas, (2018). https://mundodasmarcas.blogspot.com/2006/08/bunge-do-campo-sua-mesa.html.

Bunge. (2021) Alimentos. https://www.bunge.com.br/Marcas/Alimentos_Consumo.aspx.

Starman, A. (2013) The case study as a type of qualitative research, Journal of contemporary studies, 29-43. 